UDK 528.14

\title{
PLOKŠTUMINIŲ IR ERDVINIŲ GEODEZINIŲ KOORDINAČIŲ TRANSFORMAVIMO ALGORITMŲ TIKSLUMO ANALIZE்
}

\author{
Jonas Skeivalas ${ }^{1}$, Robertas Dargis ${ }^{2}$ \\ ${ }^{1}$ Geodezijos ir kadastro katedra, Vilniaus Gedimino technikos universitetas, \\ Sauletekio al. 11, LT-10223 Vilnius, Lietuva, \\ el.paštas: Jonas.Skeivalas@ap.vtu.lt \\ ${ }^{2} \mathrm{UAB}$,Eika“, A. Goštauto g. 40A, LT-01112 Vilnius, Lietuva, \\ el.paštas: robertas@eika.lt
}

Iteikta 200602 20, priimta 20060607

\begin{abstract}
Santrauka. Nagrinėjamas geodezinių koordinačiu, transformuojamu iš vienos koordinačių sistemos i kita, tikslumas. Transformavimo parametrų reikšmės apskaičiuojamos mažiausiujų kvadratų metodu, atsižvelgiant į identiškų taškų abiejose koordinačių sistemose tikslumą. Transformuotų i naują sistemą koordinačių tikslumas analizuojamas ivvertinant transformavimo lygčių koeficientų bei transformavimo parametrų klaidų itaką. Transformuotų koordinačių kovariacijų matrica sudaroma iš dviejų komponenčių. Viena komponentė ịvertina transformavimo lygčių koeficientų klaidu itaką, o antroji - transformavimo parametrų klaidu itaką transformuotų koordinačiu tikslumui. Pateikiamos formulès transformuotų koordinačių kovariacijų matricoms skaičiuoti.
\end{abstract}

Prasminiai žodžiai: transformavimo parametrai, kovariacijų matrica.

\section{Ivadas}

Geodezinès koordinatès iš vienos koordinačiu sistemos i kitą transformuojamos geodezinių tinklų sudarymo, kartografavimo darbuose, geoinformacinių sistemų, skaitmeninių žemėlapių kūrimo, inžinerinès geodezijos, kadastro uždaviniuose ir kt. [1-6]. Transformavimo parametrų reikšmès apskaičiuojamos mažiausiuju kvadratų metodu, taikant identiškus taškus, kurių koordinatès žinomos abiejose koordinačių sistemose. Straipsnyje nagrinèjamas transformuotu koordinačių tikslumas, ivertinant transformavimo parametrų klaidų itaką. Kovariacijų matrica sudaroma iš dviejų komponenčių. Viena iš jų rodo transformavimo lygčių koeficientu, o antroji - transformavimo parametru itaką transformuotų koordinačių kovariacijų matricai.

2. Transformavimo parametrų ir lygčių koeficientų klaidų itaka transformuotų plokštuminių koordinačių tikslumui

Plokštuminèms koordinatems transformuoti iš vienos koordinačių sistemos i kitą dažniausiai taikomas konforminis Helmerto metodas. Transformavimo parametrų reikšmėms nustatyti mažiausiujų kvadratų metodu, naudojant identišku taškų koordinates senojoje ir naujoje sistemose, sudaroma pataisų lygčių sistema:

$$
\begin{aligned}
& \boldsymbol{V}=\boldsymbol{A} \boldsymbol{\tau}+\boldsymbol{L}, \\
& \boldsymbol{L}=-\boldsymbol{T}^{\prime},
\end{aligned}
$$

čia $\quad \boldsymbol{V}=\left(V_{x_{1}}, V_{y_{1}}, \ldots, V_{x_{n}}, V_{y_{n}}\right)^{T}-$ naujosios sistemos identiškų taškų koordinačių pataisų vektorius, $\boldsymbol{T}=\left(x_{1}, y_{1}, \ldots, x_{n}, y_{n}\right)^{T}-$ koordinačių vektorius senojoje sistemoje, $\boldsymbol{T}^{\prime}=\left(x_{1}^{\prime}, y_{1}^{\prime}, \ldots, x_{n}^{\prime}, y_{n}^{\prime}\right)^{T}-$ koordinačių vektorius naujojoje sistemoje, $\quad \boldsymbol{\tau}=\left(x_{0}, y_{0}, \varepsilon_{x}, \varepsilon_{y}\right)^{T}-$ transformavimo parametru vektorius, $\left(x_{0}, y_{0}\right)$ - senosios koordinačių sistemos pradžios taško koordinatès naujojoje sistemoje, $n-$ identišku taškų skaičius, $n>k / 2, k=4-$ transformavimo parametru skaičius.

Pataisų lygčių koeficientų matrica $\boldsymbol{A}$ sudaryta iš blokų:

$$
\boldsymbol{A}=\left(\begin{array}{c}
\boldsymbol{A}_{1} \\
\vdots \\
\boldsymbol{A}_{n}
\end{array}\right),
$$

čia $\boldsymbol{A}_{i}=\left(\boldsymbol{E} \mid \boldsymbol{A}_{i}^{\prime}\right)=\left(\begin{array}{cc|cc}1 & 0 & x_{i} & -y_{i} \\ 0 & 1 & y_{i} & x_{i}\end{array}\right), \quad \boldsymbol{E}$ - vienetinè matrica.

Transformavimo parametrų vektoriaus $\boldsymbol{\tau}$ reikšmė nustatoma mažiausiujų kvadratų metodu kaip normalinių lygčiu sistemos sprendinys:

$$
\tau=-N^{-1} \omega=-N^{-1} A^{T} Q_{T^{\prime}}^{-1} L
$$

čia $\quad N=A^{T} Q_{T^{\prime}}^{-1} A, \quad \omega=A^{T} Q_{T^{\prime}}^{-1} L, Q_{T^{\prime}}-$ naujosios sistemos identiškų taškų koordinačių svorinè matrica. 
Kai pavienių taškų koordinatès nustatytos nepriklausomai viena nuo kitos,

$$
\begin{aligned}
Q_{T^{\prime}} & =\left(Q_{T_{1}^{\prime}}, Q_{T_{2}^{\prime}}, \ldots, Q_{T_{n}^{\prime}}\right)_{\text {diag }}, \\
Q_{T_{i}^{\prime}} & =\left(\begin{array}{cc}
p_{x_{i}^{\prime}}^{-1} & Q_{x_{i}^{\prime} y_{i}^{\prime}} \\
Q_{y_{i}^{\prime} x_{i}^{\prime}} & p_{y_{i}^{\prime}}^{-1}
\end{array}\right), i=1,2, \ldots, n,
\end{aligned}
$$

čia $p_{x_{i}^{\prime}}, p_{y_{i}^{\prime}}-i$-ojo taško koordinačių naujojoje sistemoje svoriai, $\quad Q_{x_{i}^{\prime} y_{i}^{\prime}}=r_{x_{i}^{\prime} y_{i}^{\prime}} p_{x_{i}^{\prime}}^{-1 / 2} p_{y_{i}^{\prime}}^{-1 / 2}, \quad r_{x_{i}^{\prime} y_{i}^{\prime}}-$ koreliacijos koeficientas.

Išlygintujų koordinačių vektorius $\tilde{\boldsymbol{T}}^{\prime}$ naujojoje sistemoje yra lygus

$$
\begin{aligned}
& \tilde{T}^{\prime}=T^{\prime}+V=T^{\prime}+A N^{-1} A^{T} Q_{T^{\prime}}^{-1} T^{\prime}-T^{\prime}= \\
& A N^{-1} A^{T} Q_{T^{\prime}}^{-1} T^{\prime}
\end{aligned}
$$

Taikydami formulę (3), gauname apskaičiuotu transformavimo parametru vektoriaus $\tau$ kovariacijų matricos išraišką:

$$
\begin{aligned}
& \boldsymbol{K}_{\tau}=\sigma_{0}^{2} \boldsymbol{Q}_{\tau}=\left(\boldsymbol{N}^{-1} \boldsymbol{A}^{\boldsymbol{T}} \boldsymbol{Q}_{\boldsymbol{T}^{\prime}}^{-1}\right) \boldsymbol{K}_{L}\left(\boldsymbol{N}^{-1} \boldsymbol{A}^{\boldsymbol{T}} \boldsymbol{Q}_{\boldsymbol{T}^{\prime}}^{-1}\right)= \\
& \sigma_{0}^{2} \boldsymbol{N}^{-1}
\end{aligned}
$$

čia $\boldsymbol{K}_{L}=\boldsymbol{K}_{\boldsymbol{T}^{\prime}}=\boldsymbol{\sigma}_{0}^{2} \boldsymbol{Q}_{\boldsymbol{T}^{\prime}}, \sigma_{0}$ - matavimo rezultato, kurio svoris lygus vienetui, standartinis nuokrypis.

Identiškų taškų išlygintujų koordinačių vektoriaus $\tilde{\boldsymbol{T}}^{\prime}$ kovariacijų matricą $\boldsymbol{K}_{\tilde{\boldsymbol{T}}^{\prime}}$, taikydami formulę (4), rašome

$$
\begin{aligned}
& K_{\tilde{T}^{\prime}}=\sigma_{0}^{2} Q_{\tilde{T}^{\prime}}=\left(A N^{-1} A^{T} Q_{T^{\prime}}^{-1}\right) K_{T^{\prime}}\left(A N^{-1} A^{T} Q_{T^{\prime}}^{-1}\right)^{T}= \\
& \sigma_{0}^{2} A N^{-1} A^{T} .
\end{aligned}
$$

Vektorių $\tilde{\boldsymbol{T}}^{\prime}$ ir $\tau$ kovariacijų matrica $\boldsymbol{K}_{\tilde{\boldsymbol{T}}^{\prime} \tau}$ yra lygi

$$
\begin{aligned}
& \boldsymbol{K}_{\tilde{T}^{\prime} \tau}=M\left\{\left(A N^{-1} A^{T} Q_{T^{\prime}}^{-1} \delta T^{\prime}\right)\left(N^{-1} A^{T} Q_{T^{\prime}}^{-1} \delta T^{\prime}\right)^{T}\right\}= \\
& \left(A N^{-1} A^{T} Q_{T^{\prime}}^{-1}\right) M\left(\delta T^{\prime} \delta T^{\prime T}\right)\left(Q_{T^{\prime}}^{-1} A N^{-1}\right)= \\
& \sigma_{0}^{2} A N^{-1} A^{T} Q_{T^{\prime}}^{-1} Q_{T^{\prime}} Q_{T^{\prime}}^{-1} A N^{-1}=\sigma_{0}^{2} A N^{-1},
\end{aligned}
$$

čia $M-$ vidurkio (matematinès vilties) simbolis, $\delta T^{\prime}=T^{\prime}-M T^{\prime}$.

Turèdami transformavimo parametru vektorių $\boldsymbol{\tau}$, galime apskaičiuoti visu kitų naujosios sistemos tašku (neidentišku) transformuotų koordinačių vektorių $\boldsymbol{T}^{\prime}$. Pavienio $i$-ojo taško koordinačių vektoriaus $\boldsymbol{T}_{\boldsymbol{i}}^{\prime}$ išraiška yra:

$$
T_{i}^{\prime}=A_{i} \tau,
$$

čia $\boldsymbol{A}_{\boldsymbol{i}}$ - koordinačių transformavimo lygčių koeficientų matrica pagal išraišką (2).

Vektoriaus $\boldsymbol{T}_{\boldsymbol{i}}^{\prime}$ kovariacijų matrica $\boldsymbol{K}_{\boldsymbol{T}_{\boldsymbol{i}}^{\prime}}$ sudaryta iš dviejų komponenčių, iš kurių viena apibrèžia transformavimo parametrų vektoriaus $\tau$ dedamujų klaidų itaką vektoriaus $\boldsymbol{T}_{\boldsymbol{i}}^{\prime}$ tikslumui, o antroji - matricos $\boldsymbol{A}_{\boldsymbol{i}}$ narių klaidų itaką vektoriaus $\boldsymbol{T}_{\boldsymbol{i}}^{\prime}$ tikslumui:

$$
\boldsymbol{K}_{T_{i}^{\prime}}=\boldsymbol{K}_{T_{i}^{\prime}(\tau)}+\boldsymbol{K}_{T_{i}^{\prime}(\boldsymbol{a})}
$$

čia $\boldsymbol{K}_{\boldsymbol{T}_{i}^{\prime}(\tau)}$ - kovariaciju matricos komponentè esant vektoriaus $\boldsymbol{\tau}$ itakai, $\boldsymbol{K}_{\boldsymbol{T}_{\boldsymbol{i}}^{\prime}(\boldsymbol{a})}-$ kovariaciju matricos komponentè esant matricos $\boldsymbol{A}_{\boldsymbol{i}}$ narių itakai.

Taikydami kovariacijų matricos $\boldsymbol{K}_{\boldsymbol{T}_{i}^{\prime}}$ komponentę $\boldsymbol{K}_{\boldsymbol{T}_{\boldsymbol{i}}^{\prime}(\tau)},(5)$, gauname:

$$
\boldsymbol{K}_{T_{i}^{\prime}(\tau)}=A_{i} K_{\tau} A_{i}^{T}=\sigma_{0}^{2} A_{i} N^{-1} A_{i}^{T}
$$

Nustatysime kovariacijų matricos komponentès $\boldsymbol{K}_{\boldsymbol{T}_{\boldsymbol{i}}^{\prime}(\boldsymbol{a})}$ išraišką. Lygybę (8) transformuojame ì kitoki pavidalą:

$$
T_{i}^{\prime}=T_{0}+M T_{i}
$$

čia $T_{0}=\left(x_{0} y_{0}\right)^{T}$. Matrica $\boldsymbol{M}$ formuojama iš transformavimo parametrų vektoriaus $\tau$ komponenčių:

$$
M=\left(\begin{array}{cc}
\varepsilon_{x} & -\varepsilon_{y} \\
\varepsilon_{y} & \varepsilon_{x}
\end{array}\right) .
$$

Taigi koeficientu matricos $\boldsymbol{A}_{\boldsymbol{i}}$ blokinès dalies $\boldsymbol{A}_{\boldsymbol{i}}^{\prime}$ nariai tapo vektoriaus $\boldsymbol{T}_{\boldsymbol{i}}$ komponentèmis. Pagal lygybę (11) galima parašyti:

$$
K_{T_{i}^{\prime}(a)}=M K_{T_{i}} M^{T},
$$

čia $\boldsymbol{K}_{\boldsymbol{T}_{\boldsymbol{i}}}-$ senos sistemos koordinačiu vektoriaus kovariacijų matrica.

Vektoriaus $\boldsymbol{T}_{0}$, kaip transformavimo parametru vektoriaus $\boldsymbol{\tau}$ komponentès, įtaka išreikšta formule (10).

\section{Transformavimo parametrų ir lygčių koeficientų klaidų įtaka transformuotų erdvinių koordinačių tikslumui}

Erdvinių koordinačių transformavimo lygčių sistema yra netiesinè, todèl praktiniuose skaičiavimuose ji linearizuojama ir rašoma taip (esant $i$-ojo taško koordinatèms):

$$
\left.\begin{array}{l}
\boldsymbol{T}_{\boldsymbol{i}}^{\prime}=\boldsymbol{T}_{\boldsymbol{i}}+\boldsymbol{A}_{\boldsymbol{i}} \tau \\
i=1,2, \ldots, n
\end{array}\right\}
$$


čia $\boldsymbol{T}_{i}^{\prime}=\left(x_{i}^{\prime}, y_{i}^{\prime}, z_{i}^{\prime}\right)^{T}-i$-ojo taško koordinačių vektorius naujoje sistemoje, $\boldsymbol{T}_{i}=\left(x_{i}, y_{i}, z_{i}\right)^{T}-i$-ojo taško koordinačiu vektorius senojoje sistemoje, $\boldsymbol{\tau}=\left(x_{0} y_{0} z_{0} \varepsilon_{x} \varepsilon_{y} \varepsilon_{z} m\right)^{T}-$ transformavimo parametru vektorius, $m$ - linijinis mastelis, $n$ - identišku tašku skaičius, kai skaičiuojami transformavimo parametrai.

Matrica

$$
\boldsymbol{A}_{i}=\left(\boldsymbol{E} \mid \boldsymbol{A}_{i}^{\prime}\right)=\left(\begin{array}{ccc|cccc}
1 & 0 & 0 & 0 & -z_{i} & y_{i} & x_{i} \\
0 & 1 & 0 & z_{i} & 0 & -x_{i} & y_{i} \\
0 & 0 & 1 & -y_{i} & x_{i} & 0 & z_{i}
\end{array}\right)
$$

Transformavimo parametrų vektoriaus $\tau$ reikšmè gaunama mažiausiujų kvadratų metodu kaip normalinių lygčių sistemos sprendinys, taikant $n$ identiškų tašku duomenis:

$$
\tau=-N^{-1} \omega
$$

čia $\quad \boldsymbol{N}=\boldsymbol{A}^{\boldsymbol{T}} \boldsymbol{Q}_{\boldsymbol{T}^{\prime}}^{-1} \boldsymbol{A}, \quad \boldsymbol{\omega}=\boldsymbol{A}^{\boldsymbol{T}} \boldsymbol{Q}_{\boldsymbol{T}^{\prime}}^{-1} \boldsymbol{L}, \quad \boldsymbol{L}=\left(L_{1}^{T} \ldots L_{n}^{T}\right)^{T}-$ laisvuju narių vektorius, $L_{i}=T_{i}-T_{i}^{\prime}$. Pataisų lygčių koeficientų matrica $\boldsymbol{A}$ sudaryta iš bloku

$$
\boldsymbol{A}=\left(\begin{array}{c}
\boldsymbol{A}_{1} \\
\boldsymbol{A}_{2} \\
\vdots \\
\boldsymbol{A}_{n}
\end{array}\right)
$$

Apskaičiuotų transformavimo parametrų vektoriaus $\boldsymbol{\tau}$ kovariacijų matrica $\boldsymbol{K}_{\tau}$ yra lygi [7]:

$$
\boldsymbol{K}_{\tau}=\sigma_{0}^{2}\left(\boldsymbol{N}^{-1} \boldsymbol{N}_{1} \boldsymbol{N}^{-1}+\boldsymbol{N}^{-1}\right)
$$

čia $N_{1}=A^{T} Q_{T^{\prime}}^{-1}, Q_{T} Q_{T^{\prime}}^{-1} A, \quad Q_{T}-$ senosios sistemos identiškų taškų koordinačių svorinè matrica.

Tuo atveju, kai naujosios ir senosios sistemu identiškų taškų koordinatès yra maždaug vienodo tikslumo, t. y. $\boldsymbol{Q}_{\boldsymbol{T}^{\prime}} \approx \boldsymbol{Q}_{\boldsymbol{T}}$, tada $N_{1}=N$, ir formule (18) rašoma:

$$
\boldsymbol{K}_{\tau}=2 \sigma_{0}^{2} \boldsymbol{N}^{-1}
$$

Pavienio $i$-ojo taško erdvinių koordinačių vektoriui $\boldsymbol{T}_{\boldsymbol{i}}$ transformuoti į naujają koordinačių sistemą taikysime transformavimo formulę, kuri iš pavidalo (14) pertvarkyta taip:

$$
\boldsymbol{T}_{i}^{\prime}=\boldsymbol{T}_{0}+(\boldsymbol{E}+\boldsymbol{M}) \boldsymbol{T}_{i}
$$

čia $\boldsymbol{T}_{0}=\left(x_{0} y_{0} z_{0}\right)^{T}-$ viena transformavimo parametru vektoriaus $\boldsymbol{\tau}$ dedamoji. Matrica $\boldsymbol{M}$ sudaroma iš transformavimo parametrų vektoriaus $\boldsymbol{\tau}$ antrosios dedamosios ir užrašoma taip:

$$
M=\left(\begin{array}{ccc}
m & \varepsilon_{z} & -\varepsilon_{y} \\
-\varepsilon_{z} & m & \varepsilon_{x} \\
\varepsilon_{y} & -\varepsilon_{x} & m
\end{array}\right)
$$

Transformuojant erdvines koordinates naujojo vektoriaus $\boldsymbol{T}_{\boldsymbol{i}}^{\prime}$ kovariacijų matrica $\boldsymbol{K}_{\boldsymbol{T}_{i}^{\prime}}$ sudaryta iš dviejų komponenčių $-\boldsymbol{K}_{\boldsymbol{T}_{i}^{\prime}(\tau)}$ ir $\boldsymbol{K}_{\boldsymbol{T}_{\boldsymbol{i}}^{\prime}(\boldsymbol{a})}$ :

$$
\boldsymbol{K}_{\boldsymbol{T}_{i}^{\prime}}=\boldsymbol{K}_{\boldsymbol{T}_{i}^{\prime}(\tau)}+\boldsymbol{K}_{\boldsymbol{T}_{i}^{\prime}(\boldsymbol{a})}
$$

Kovariaciju matricos komponentè $\boldsymbol{K}_{\boldsymbol{T}_{\boldsymbol{i}}^{\prime}(\tau)}$ rodo transformavimo parametrų vektoriaus $\tau$ ittaką vektoriaus $\boldsymbol{T}_{\boldsymbol{i}}^{\prime}$ tikslumui. Antroji komponentè $\boldsymbol{K}_{\boldsymbol{T}_{\boldsymbol{i}}^{\prime}(\boldsymbol{a})}$ apibūdina matricos $\boldsymbol{A}_{\boldsymbol{i}}$ narių itaką vektoriaus $\boldsymbol{T}_{\boldsymbol{i}}^{\prime}$ tikslumui.

Kovariaciju matricos komponente $\boldsymbol{K}_{\boldsymbol{T}_{i}^{\prime}(\tau)}$, taikant formulę (14), rašoma:

$$
\boldsymbol{K}_{T_{i}^{\prime}(\tau)}=\boldsymbol{K}_{T_{i}}+A_{i} K_{\tau} A_{i}^{T}=K_{T_{i}}+2 \sigma_{0}^{2} A_{i} N^{-1} A_{i}^{T}
$$

kai identiškiems taškams galioja apytikrè lygybė $\boldsymbol{Q}_{\boldsymbol{T}^{\prime}} \approx \boldsymbol{Q}_{\boldsymbol{T}}, \boldsymbol{K}_{\boldsymbol{T}_{\boldsymbol{i}}}-$ senos sistemos koordinačių vektoriaus kovariacijų matrica.

Kovariacijų matricos komponentè $\boldsymbol{K}_{\boldsymbol{T}_{i}^{\prime}(\boldsymbol{a})}$, taikant formulę (20), igauna išraišką

$$
\boldsymbol{K}_{T_{i}^{\prime}(a)}=(E+M) K_{T_{i}}(E+M)^{T} .
$$

Pateiksime pavyzdi transformuotu plokštuminių koordinačių tikslumui dėl transformavimo parametrų bei transformavimo lygčių koeficientų klaidų įtakos įvertinti. Transformavimo parametrų vektoriaus $\tau$ reikšmè nustatyta pagal 7 identiškus taškus ir lygi:

$$
\boldsymbol{\tau}=\left(\begin{array}{c}
6039264,438 \\
553665,202 \\
0,99979550316 \\
1,83813 \cdot 10^{-6}
\end{array}\right) \text {. }
$$

Vektoriaus $\boldsymbol{\tau}$ kovariacijų matricos $\boldsymbol{K}_{\tau}$ ịvertis $\boldsymbol{K}_{\tau}^{\prime}$ yra lygus

$$
\begin{aligned}
& \boldsymbol{K}_{\tau}^{\prime}=m_{0}^{2} N^{-1}=1,7 \cdot 10^{-6}(0,143 ; 0,143 \\
& \left.0,368 \cdot 10^{-9} ; 0,368 \cdot 10^{-9}\right)_{\text {diag }},
\end{aligned}
$$

čia $\sigma_{0} \approx m_{0}$, atvirkštinès matricos $N^{-1}$ nediagonalieji nariai yra artimi nuliui. 
Transformuotų koordinačių standartinių nuokrypių įverčiai Estimations of standard deviations of transformed coordinates

\begin{tabular}{|c|c|c|c|c|c|c|}
\hline Taško Nr. & \multicolumn{6}{|c|}{ Standartinių nuokrypiu iverčiai, m } \\
\cline { 2 - 7 } & $m_{x^{\prime}(\tau)}$ & $m_{y^{\prime}(\tau)}$ & $m_{x^{\prime}(a)}$ & $m_{y^{\prime}(a)}$ & $m_{x^{\prime}}=\sqrt{m_{x^{\prime}(\tau)}^{2}+m_{x^{\prime}(a)}^{2}}$ & $m_{y^{\prime}}=\sqrt{m_{y^{\prime}(\tau)}^{2}+m_{y^{\prime}(a)}^{2}}$ \\
\hline 1 & 0,001 & 0,001 & 0,002 & 0,001 & 0,0022 & 0,0014 \\
\hline 2 & 0,001 & 0,001 & 0,002 & 0,001 & 0,0022 & 0,0014 \\
\hline
\end{tabular}

Transformuojamų 2 taškų koordinačių transformavimo lygčių koeficientų matrica yra lygi:

$$
A=\left(\begin{array}{l}
A_{1} \\
A_{2}
\end{array}\right)=\left(\begin{array}{ll|lc}
1 & 0 & 30993,640 & -21255,800 \\
0 & 1 & 21255,800 & 30993,640 \\
1 & 0 & 30869,460 & -21061,820 \\
0 & 1 & 21061,820 & 30869,460
\end{array}\right) .
$$

Kovariaciju matricos komponentès $\boldsymbol{K}_{\boldsymbol{T}^{\prime}(\tau)}$ iverti $\boldsymbol{K}_{\boldsymbol{T}^{\prime}(\tau)}^{\prime}$ esant transformavimo parametrų klaidų itakai gauname pagal formulę (10), kai $\sigma_{0} \approx m_{0}$ :

$$
\begin{aligned}
& \boldsymbol{K}_{\boldsymbol{T}^{\prime}(\tau)}^{\prime}=\boldsymbol{A} \boldsymbol{K}_{\tau}^{\prime} \boldsymbol{A}^{\boldsymbol{T}}=1,7 \cdot 10^{-6}(0,658 ; 0,658 \\
& 0,657 ; 0,657)_{\text {diag }}
\end{aligned}
$$

nediagonalieji nariai paprastai yra lygūs nuliui.

Kovariaciju matricos komponentès $\boldsymbol{K}_{\boldsymbol{T}^{\prime}(\boldsymbol{a})}$ ịvertis $\boldsymbol{K}_{\boldsymbol{T}^{\prime}(\boldsymbol{a})}^{\prime}$ esant transformavimo lygčių koeficientų klaidų itakai nustatomas pagal formulę (13):

$$
\boldsymbol{K}_{\boldsymbol{T}^{\prime}(\boldsymbol{a})}^{\prime}=\boldsymbol{M \boldsymbol { K } _ { T }} \boldsymbol{M}^{\boldsymbol{T}}=10^{-6}\left(\begin{array}{ll}
4 & 4 \\
4 & 1
\end{array}\right) \text {. }
$$

Šioje formulèje

$$
\begin{aligned}
& \boldsymbol{M}=\left(\begin{array}{cc}
0,99 & -1,8 \cdot 10^{-6} \\
1,8 \cdot 10^{-6} & 0,99
\end{array}\right), \\
& \boldsymbol{K}_{\boldsymbol{T}}=10^{-6}\left(\begin{array}{cc|c}
4 & 4 & \\
4 & 1 & 0 \\
\hline 0 & 4 & 4 \\
4 & 1
\end{array}\right)
\end{aligned}
$$

I naują sistemą transformuotu taškų koordinačių standartinių nuokrypių íverčiai $m_{x^{\prime}}, m_{y^{\prime}}$ pateikti lentelèje.

\section{Išvados}

1. Gautos formulès i naują sistemą transformuotų plokštuminių ir erdvinių koordinačių tikslumui įvertinti kovariacijų matricos pavidalu, kai atsižvelgiama ne tik $\mathfrak{i}$ transformavimo parametru klaidu, bet ir transformavimo lygčių koeficientų klaidų itaką.

2. Išvestosios formulès rodo, kad transformuotosios i naujają sistemą plokštuminès ir erdvinès koordinatės yra mažiau tikslios už senosios sistemos koordinates.
Transformuotujų koordinačių tikslumas labiausiai priklauso nuo transformavimo parametru nustatymo tikslumo, o jis nuo identiškų taškų skaičiaus bei šių taškų koordinačių abiejose sistemose tikslumo. Skaičiavimų rezultatai rodo, kad transformavimo lygčiu koeficientų klaidu itaka transformuotu koordinačių tikslumui yra maždaug tos pačios eilès kaip ir transformavimo parametrų klaidų įtaka.

\section{Literatūra}

1. Koch, K.-R. Räumliche Helmert-Transformation variabler Koordinaten im Gauss-Helmert und im Gauss-Markoff Modell. Z. f. Vermessungswessen, No 3. Stuttgart: Verlag K. Witwer, 2002, S. 147-152.

2. Koch, K.-R. Einführung in die Bayes-Statistik. Berlin Heidelberg: Springer-Verlag, 2000. 225 S.

3. Fischer, B.; Hegland, M. Collocation, filtering and nonparametric regression, Part 1. Z. f. Vermessungswessen, No 1. Stuttgart: Verlag K. Witwer, 1999, S. 17-24.

4. Chitau, D. Über Koordinatentransformation in dreidimensionalen Systemen mit linearen Modellen. $Z . \quad f$. Vermessungswessen, No 5, Stuttgart: Verlag K. Witwer, 1996, S. 203-211.

5. Skeivalas, J.; Putrimas, R. Accuracy analysis of planimetric coordinate transformation. Geodesy and Cartography (Geodezija ir kartografija), No 1 (23). Vilnius: Technika, 1996, p. 92-95 (in Lithuanian).

6. Markuze, J. J.; Bojko, E. G.; Golubev, V. V. Geodesy. Computation and adjustment of geodetic networks. Moscow: Kartgeocentr-Geodezizdat, 1994. 432 p. (in Russian).

7. Skeivalas, J. Accuracy of 3D geodetic coordinates transformation algorithmus. Geodesy and Cartography (Geodezija ir kartografija), Vol XXXI, No 2. Vilnius: Technika, 2005, p. 54-56 (in Lithuanian).

Jonas SKEIVALAS. Prof, Doctor Habil.

Vilnius Gediminas Technical University. Dept of Geodesy and Cadastre, Saulètekio al. 11, LT-10223 Vilnius, Lithuania $(\mathrm{Ph}+3705274$ 4703, Fax +370 5274 4705),

e-mail: jonas.skeivalas@ap.vtu.lt.

Author of two monographs and more than 130 scientific papers. Participated in many intern conferences and research visits to the Finish Geodetic Institute.

Research interests: processing of measurements with respect to tolerances, adjustment of geodetic networks.

Robertas DARGIS. Engineer. UAB „Eika“, A. Goštauto g. 40A, LT-01112 Vilnius, Lietuva.

Research interests: engineering geodesy, adjustment of geodetic networks. 